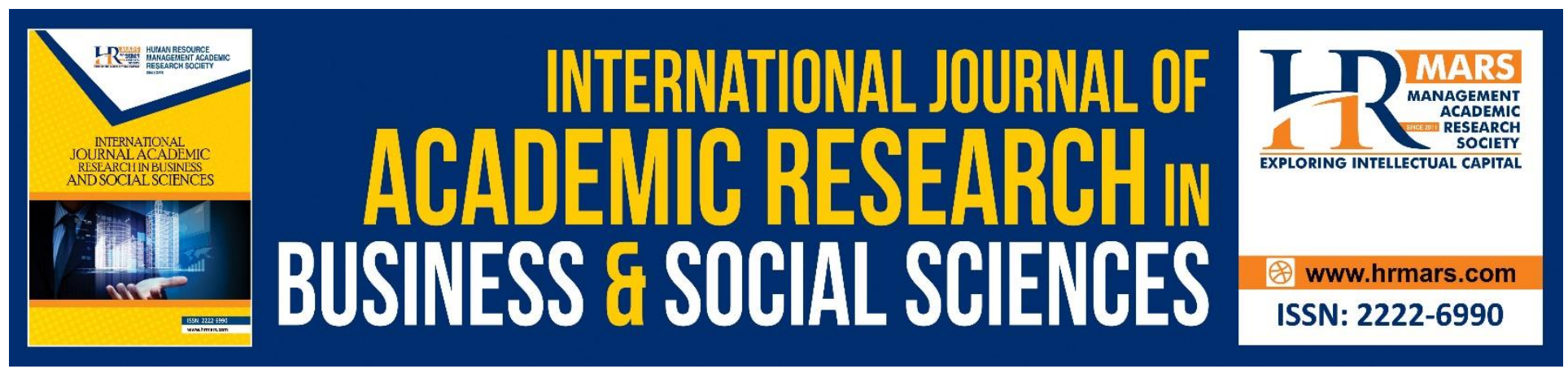

\title{
Self-Concept of Young Offenders Undergoing Non-Custodial Sentences in Malaysia
}

\section{N. K. Tharshini, Fauziah Ibrahim, Ezarina Zakaria}

To Link this Article: http://dx.doi.org/10.6007/IJARBSS/v11-i14/8571 DOI:10.6007/IJARBSS/v11-i14/8571

Received: 05 November 2020, Revised: 08 December 2020, Accepted: 31 December 2020

Published Online: 29 January 2020

In-Text Citation: (Tharshini et al., 2021)

To Cite this Article: Tharshini, N. K., Ibrahim, F., \& Zakaria, E. (2021). Self-Concept of Young Offenders Undergoing Non-Custodial Sentences in Malaysia. International Journal of Academic Research in Business and Social Sciences, 11(14), 245-255.

Copyright: (C) 2021 The Author(s)

Published by Human Resource Management Academic Research Society (www.hrmars.com)

This article is published under the Creative Commons Attribution (CCBY 4.0) license. Anyone may reproduce, distribute, translate and create derivative works of this article (for both commercial and non-commercial purposes), subject to full attribution to the original publication and authors. The full terms of this license may be seen

at: http://creativecommons.org/licences/by/4.0/legalcode

Special Issue: Contemporary Business and Humanities Landscape Towards Sustainability, 2021, Pg. 245 - 255 http://hrmars.com/index.php/pages/detail/IJARBSS JOURNAL HOMEPAGE

Full Terms \& Conditions of access and use can be found at http://hrmars.com/index.php/pages/detail/publication-ethics 


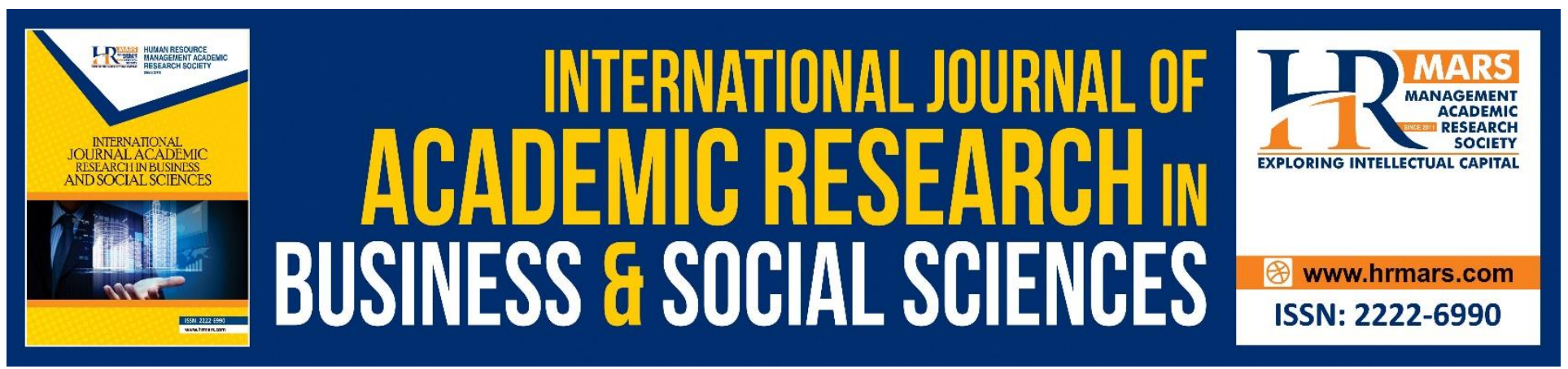

\title{
Self-Concept of Young Offenders Undergoing Non- Custodial Sentences in Malaysia
}

\author{
N. K. Tharshini, Fauziah Ibrahim
}

Faculty of Social Sciences and Humanities, Universiti Malaysia Sarawak, 94300 Kota Samarahan, Sarawak, Malaysia

\section{Ezarina Zakaria}

Faculty of Social Sciences and Humanities, Universiti Kebangsaan Malaysia, 43600 Bangi, Selangor, Malaysia

Email: stharshini@unimas.my

\begin{abstract}
Self-concept provides great empirical value in order to understand criminal behaviour among young offenders. Hence, this article is prepared to discuss the level of self-concept of young offenders undergoing non-custodial sentences in Malaysia. A quantitative approach was employed to collect data among 311 young offenders undergoing Community Service Order initiated by the Malaysian Social Welfare Department. Statistical Package for the Social Sciences (SPSS) was used to analyse the data. The result stipulates that majority of the respondents consist of male young offenders aged 20 years old, Malays, single in marital status, and unemployed. The finding also unveiled that young offenders have a moderate level of self-concept (76.2\%). As a part of the key recommendation, the Malaysian Social Welfare Department is adjured to revamp the existing Community Service Order module and program in order to improvise the level of self-concept of the young offenders in the near future.
\end{abstract}

Keywords: Self-Concept, Young Offenders, Non-Custodial, Malaysia

\section{Introduction}

In recent years, studies focusing on self-concept have managed to captivate an incredible amount of attention across scientific disciplines. A handful number of studies have disclosed that both positive and negative self-concept is a reflection of various life experiences encountered by an individual beginning from childhood to adolescence stage of life (Koiv, 2016; Veiga et al. 2016; Laceulle, 2018; Edwardes, 2019). Findings postulate that a negative self-concept contributes to detrimental life outcomes including involvement in criminal behaviour, tend to rebukes authorities, and highly inclined to reject the social norms established by the society whereas a positive self-concept 
contributes to the development of positive self-image and high level of self-esteem (Veiga et al. 2016; Debono et al. 2020).

In general, an individual's level of self-concept is strongly correlated with the quality of relationship between their friends and parents (Oluwasanmi \& Babatola, 2018). Koiv (2016) stated that young people need a higher amount of emotional support from their parents in order to develop a positive self-concept eventually reduces the risk of getting involved in criminal activities. Substantial evidence implicates that the omission of mutually supportive parents-children relationship creates an "emotion vacuum" among young adult and escalate the tendency of isolating themselves from family members (Koiv, 2016). Indirectly, this situation leads the young adult to completely rely on the peer group to obtain the "missing support" eventually ending up embracing the standard and values of the peer group as time goes by. Admittedly, if the peer culture is deviant and the connection to parental support is frail thus the young adult becomes highly vulnerable to commit antisocial behaviour (Koiv, 2016; Schildberg-Horisch, 2018).

Myriad scholars have taken enormous attempts to understand the young offender's personality and behaviour. For instance, Symbolic Interactionism Theory founded by George Herbert Mead (18631931) proposes that stigma and labels influence an individual's self-concept (Abele \& Hauke, 2020). Some research indicates that after being labelled by others, individuals tend to increase their involvement in criminal behaviour and internalized the "offender" label (Abele \& Hauke, 2020). On this line of thought, Paterline and Orr (2016) stated that young offenders who have been ordered to complete custodial sentences (e.g. imprisonment) are highly exposed to stigmatization and encountered enormous assaults due to depersonalizing effects of the legal system compared to those serving non-custodial sentences such as Community Service Order (CSO).

The introduction of non-custodial sentences in Wales and England in 1973 has led to considerable debate among the scholars whether non-custodial sentences should be accepted as a form of alternative custody or otherwise. However, over the last two-decade non-custodial sentences such as CSO have gained acceptance within the criminal justice system as a non-institutionalized form of alternative punishment and regarded to be efficacious in reducing imprisonment rate among young offenders (Phelps, 2018). In general, the main goal of CSO with regards to young offenders is to develop and rehabilitate positive attitude, competency, and behaviour within the young adults who have committed minor crimes (Phelps, 2018). Moreover, according to Mata et al. (2018) assistance need to be provided to the young offenders in order to help them to reinforce good habits and improvise their ability of communication, cooperation, and self-esteem.

In the context of Malaysia, the CSO was introduced in the year 2007 for young offenders aged between 18 to 21 years old. In general, CSO is sentences to first-timers who have commit minor crimes as stated in Section 293 (1) (e) of the Criminal Procedure Code (Act 593). Moreover, Section 96 (2) of the Child Act (2001) clearly mentioned that children aged between 14 to 18 years old should be prevented from being sentence in prison and other types of alternative punishment such as fines or non-custodial sentence (e.g. CSO) is suggested for them (Child Act, 2001). Since literature related to young offenders serving non-custodial sentences such as CSO received little attention compared 
to those serving custodial sentences (e.g. prison) ergo this research will focus on the young offenders undergoing CSO in Malaysia. Moreover, most of the previous studies related to self-concept and crime have been carried out in Western countries particularly in the USA and UK. According to Vignoles et al. (2016), people from different cultures tend to think about themselves in a different way. Hence, the findings obtained from the Western studies in regards to self-concept and crime may not be suitable to generalize to non-Western cultures like Malaysia. Thus, this research is conducted to identify the level of self-concept of young offenders undergoing CSO in an Asian country like Malaysia.

\section{Literature Review}

The construct of self-concept has been a topic of great interest in the field of criminology since it has a pervasive impact on human behaviour. Previously, self-concept was conceptualized as a unidimensional construct however in recent time's self-concept has been acknowledged as a multidimensional construct (Veiga et al. 2016). In general, self-concept includes various dimensions related to the "self" that reflect an individual profuse life experience and roles (Chu, 2017). According to Shavelson et al. (1976), self-concept is defined as a person's self-perceptions formed through one's interpretations and experience with his/her environment. Moreover, Shavelson et al. (1976) identified seven main features of self-concept namely; (a) multifaceted nature, (b) theoretical organization, (c) evaluative underpinnings, (d) hierarchical structure, (e) differentially from other structure, (f) developmental nature, and (g) stability.

Growing evidence indicates that criminal act is conceptualized as a simple, short-lived, exciting, and a tool to gain immediate gratification (Paterline \& Orr, 2016). In the attempt to elucidate the link between self-concept and criminal behaviour, researchers usually subscribed to two school of thoughts namely; (i) criminal behaviour is the product of low self-concept, or (ii) self-concept is the product of an individual's criminal behaviour (Rosenberg, 1979). Prior literature both in psychology and criminology depicted that "self" is an intervening key which conditions the likelihood of an individual to dwell in criminal activities (Mata et al. 2018). As such, Koive (2016) stated that low selfconcept is related to low school competence and high family conflict/dispute whereas high selfconcept is significantly related to positive friendships circle among young adults. Studies have also unveiled that adolescents suspended from school exhibit low self-concept, low verbal ability, and a negative view of self (Koive, 2016).

In general, individual with a negative self-concept is not concerned about the long-term consequences of their behaviour thus gets involved in criminal activities (Paterline et al. 2016; Veiga et al. 2016; Mata et al. 2018; Edwardes, 2019; Abele et al. 2020). Previous studies show that young adult's antisocial behaviour predicts long-term consequences towards criminal activity especially when they reach the adulthood phase of life (Augustyn \& Jackson, 2017; Mohammadi et al., 2014). Moreover, according to Meldrum et al. (2016), family plays an important role in forming and strengthening a positive self-concept of an individual. In line with this, a study conducted by Augustyn and Jackson (2017) shows that individuals who grew up in a weak family functioning tend to have a lower level of self-concept, develop a pessimistic attitude towards life, and practices negative coping behaviour. 
In many countries, the prison system is undergoing major challenges due to overcrowding and deplorable conditions of the detention center. Apart from imprisonment, judicial systems have a range of non-custodial sentence options for those who have committed minor crimes such as nuisances, disorderly conduct, fraudulent possession of property, insulting behaviour, or offenses in relation to public roads (Minor Offences Act, 1955, Act 336). Human Rights in the Administration of Justice (2019) have pointed out that individuals who have committed a minor crime should not be sent to prison since it hinders the process of reintegration and weakens the community ties. Hence, non-custodial sentences such as CSO should be considered as a form of punishment while sentencing an individual since this approach have a unique measure to change perpetrators antisocial behaviour. (Human Rights in the Administration of Justice).

\section{Methods}

This section discusses the methodology that was utilized in the research process.

\section{Research Design}

This study is based on a quantitative method using a cross-sectional approach. According to Belhekar (2016), data should be collected at one particular time while employing a cross-sectional approach.

\section{Population, Sample and Location of Study}

In research terminology, a population is defined as a comprehensive group of individuals with a common characteristic (Belhekar, 2016). The population of this study is consists of all the young offenders undergoing CSO initiated by the Malaysian Social Welfare Department. Based on the report derived from the Malaysian Social Welfare Department, currently a total number of 540 young offenders are actively undergoing CSO in Malaysia (Community Service Order Report, 2018).

In general, a sample is defined as a smaller subset from a larger population (Cohen et al. 2001). The sample for this study is 311 respondents determined based on Cohen's Sample Size Calculator (Cohen et al. 2001). Following this, stratified random sampling was used to select the young offenders from four different zones in Malaysia namely (i) North Zone, (ii) Central Zone, (iii) East Zone, and (iv) Southern Zone. Two institutions with the highest number of young offenders within each zone were selected as the location of study including; (i) North Zone - Kedah and Pulau Pinang, (ii) Central Zone - Selangor and Federal Territory of Kuala Lumpur, (iii) East Zone - Pahang and Kelantan, and (iv) Southern Zone - Melaka and Johor. Table 1 shows the location of the study. 


\begin{tabular}{|c|c|c|}
\hline Zone & $\begin{array}{l}\text { Social Welfare Department } \\
\text { (SWD) }\end{array}$ & $\begin{array}{l}\text { Population of Young } \\
\text { Offenders }\end{array}$ \\
\hline \multirow[t]{4}{*}{ North } & SWD in Perlis & 13 \\
\hline & SWD in Kedah & 48 \\
\hline & SWD in Pulau Pinang & 36 \\
\hline & SWD in Perak & 20 \\
\hline \multirow[t]{4}{*}{ Central } & SWD in Negeri Sembilan & $\begin{array}{l}64 \text { (this populations were } \\
\text { excluded during the data }\end{array}$ \\
\hline & SWD in Selangor & collection - pilot study) \\
\hline & SWD in Federal Territory of & 72 \\
\hline & Kuala Lumpur & 68 \\
\hline \multirow[t]{3}{*}{ East } & SWD in Pahang & 79 \\
\hline & SWD in Kelantan & 36 \\
\hline & SWD in Terengganu & 25 \\
\hline Souther & SWD in Melaka & 42 \\
\hline \multirow[t]{2}{*}{$n$} & SWD in Johor & 37 \\
\hline & TOTAL & 540 \\
\hline
\end{tabular}

Table 1: Location of the Study

\section{Research Instrument}

The self-concept of young offenders is measured using the Multidimensional Self-Concept Scale developed by Fleming and Courtney (1984) which includes 36 items questions. Based on this Multidimensional Self-Concept Scale, self-concept is divided into five main dimensions namely; (i) self-regards (global self-esteem), (ii) social confidence, (iii) school abilities, (iv) physical appearance, and (v) physical abilities.

\section{Procedure}

The questionnaire was distributed to the respondents by the researchers upon getting permission from the Malaysian Department of Social Welfare (JKMM 100/12/2/2:2016/013). The confidentiality and anonymity of respondents were handled with utmost care throughout the research. Moreover, respondents were also reminded not to disclose their personal information on the given material (e.g. name or Malaysian identity card number). Generally, majority of the respondents took about 15-20 minutes to complete the questionnaire.

\section{Data Analysis}

Statistical Package for the Social Sciences (SPSS) was employed to analyze the data. In general, descriptive analyses were used to present information related to young offenders demographic profile and level of self-concept. The score range for the level of self-concept is divided into three main categories namely; (i) low self-concept (<2.33), (ii) moderate self-concept (2.34-3.67), and (iii) high self-concept (3.68-5.00). 


\section{Ethical Considerations}

The following ethical consideration was upheld throughout the data collection process:

(i) Participants are allowed to withdraw from the study without any repercussions.

(ii) Consent from the participant was obtained before allowing them to take part in this study.

(iii) No incentives or benefits were given to encourage participation.

(iv) Participants were assured that all the information obtained from this study will be only used for academic purpose and handled with utmost confidentiality.

\section{Results}

This section reports the result of the analyzed data. The first part of the result shows the demographic composition of the respondents whereas the second section presents the descriptive statistics pertaining to the level of self-concept of young offenders undergoing CSO.

\section{Demographic Profile}

The demographic profile represents the basic information of the respondents who took part in this study. The result of the descriptive analysis shows that majority of the respondents are male young offenders aged 20 years old, Malays, single in marital sta tus, and unemployed. Table 2 stipulates the demographic profile of the respondents.

\begin{tabular}{lcc}
\hline Variable (s) & Frequency & Percentage (\%) \\
\hline Gender & 311 & 100 \\
Male & & \\
Age & 55 & 17.7 \\
18 years & 83 & 26.6 \\
19 years & 111 & 35.7 \\
20 years & 62 & 20.0 \\
21 years & & \\
Ethnic Group & 278 & 89.3 \\
Malay & 17 & 5.5 \\
Indian & 16 & 5.2 \\
Chinese & & \\
Marital Status & 289 & 93.0 \\
Single & 22 & 7.0 \\
Married & & \\
Occupation & 43 & 13.8 \\
Student & 152 & 48.9 \\
Unemployed & 55 & 17.7 \\
Full-Timer & 61 & 19.6 \\
Part-Timer & $\mathbf{3 1 1}$ & $\mathbf{1 0 0}$ \\
\hline TOTAL &
\end{tabular}

Table 2: Demographic Profile 
INTERNATIONAL JOURNAL OF ACADEMIC RESEARCH IN BUSINESS AND SOCIAL SCIENCES

Vol. 11, No. 14, Contemporary Business and Humanities Landscape Towards Sustainability. 2021, E-ISSN: 2222-6990 @ 2021 HRMARS

Level of Self-Concept

The result of the descriptive analysis indicates that majority of the young offenders undergoing CSO have a moderate level of self-concept (76.2\%). Table 3 stipulates the level of self-concept of the respondents.

\begin{tabular}{lcc}
\hline Level of Self-Concept & Frequency & Percentage (\%) \\
\hline Low & 54 & 17.4 \\
Moderate & 237 & 76.2 \\
High & 20 & 6.4 \\
\hline
\end{tabular}

Note: Low (<2.33), Moderate (2.34-3.67), High (3.68-5.00)

Table 3: Level of Self-Concept

\section{Discussion}

A handful number of studies have reported that on average rate, males involved more in criminal offending compared to females (Burris et al. 2017). The result of this study is aligned with "age-crimecurve" showing that the criminal activities of an individual peak during the mid-20s before declining thereafter. In general, majority of the respondents involved in this study are unemployed. Lack of responsibility might lead the young offenders to dwell in antisocial behaviour. For young people who are single, imprisonment or convictions have less impact on them compared to those who are committed in a relationship or married (Skardhamar et al. 2015). It is prognosticated that conformity to a peer group or peer pressure might have encouraged young adults to participate in criminal act. Admittedly, the lifestyle (e.g. frequent users of drugs or visiting clubs/pubs) of the younger generation is also foreseen as a possible reason for them to get involved in criminal behaviour such as minor thefts, joyriding, or shoplifting.

A large number of respondents agree with the statements in the self-concept questionnaire. Around $52.4 \%$ of young offenders feel confident with their abilities and believed that someday people will look up and respect them. Young offenders admit that they are aware of the good and bad things done in the past $(46.7 \%)$ and are confident that other people see them as physically appealing (38.3\%). In addition, 39.5\% of young offenders agree that they are not troubled by shyness and feel comfortable meeting new people (37.1\%). Around $29.4 \%$ of young offenders concur that they never felt ashamed of their physique whereas $23.1 \%$ of young offenders felt that they are physically attractive compared to their peers. The findings of this research coincide with some previous studies showing that there is a significant relationship between self-concept and individual life experience (Koiv, 2016). Meldrum et al. (2016) stated that the self-concept of an individual is formed through the life experience encountered from childhood until the adolescent phase of life. Thus, it can be fairly concluded that majority of the young offenders who took part in this study have encountered positive character-building experiences throughout their life since most of the young offenders are able to internalize a "positive self-image" about themselves.

Edwardes (2019) stated that positive self-concept significantly contribute towards improved cognitive and emotional development and ameliorate individual functionality in society. In general, the main goal of non-custodial sentences such as CSO with regards to young offenders is to help them develop positive behaviour, attitude, and competency in order to become a responsible member of 
the society in future (Phelps, 2018). The positive self-concept of young offenders is foreseeable as a catalyst factor in reinforcing good habits and increases respondent's communication and cooperation skills while undergoing CSO. Furthermore, according to Koiv (2016) and Meldrum et al. (2016), a positive self-concept can be strengthened if young offenders receive continuous support from the social environment.

However, not all the young offenders involved in this study have a positive self-concept. The result of this study depicts that around $32.1 \%$ of young offenders perceive themselves as worthless and often dislike themselves (23.4\%). Besides, 39.7\% of young offenders concur that they often feel discouraged and doubt about their worthwhileness. According to Koiv (2016), low self-concept is a product of negative perception about oneself. Koiv (2016) further explained that individuals with low self-concept will encounter low self-esteem, low self-control, self-doubt, prefer being isolated from the social environment, and often feel uncomfortable to communicate with others. In the context of this study, since majority of the young offenders are aged between 18 to 21 years old, it is conjecture that young people have limited ability to control negative perceptions about themselves due to lack of matureness. Moreover, since young offenders are still undergoing a critical stage of development, it is common for them to experience continuous changes mentally and psychologically (Meldrum et al. 2016; Phelps, 2018).

Numerous studies that link between self-concept and criminal behaviour shows that compared to the general public, the level of self-concept of the young offenders is naturally lower (Burris et al. 2017; Mata et al. 2018). The labelling or stigmatization experienced while undergoing non-custodial sentences might also contributes towards the development of low self-concept among young offenders. The Self-Theory suggested that the fundamental motivation of human being is to maintain and protect a positive self-image (Mata et al. 2018). Hence, it can be recapitulated that the low selfconcept exhibited by the young offenders is probably due to their inability to maintain a "positive self-image" in front of their peers, family members, or society.

\section{Conclusion}

In summary, the finding of this study raises some important understanding regarding the level of selfconcept of young offenders undergoing non-custodial sentences in Malaysia. In the process of completing the sentences, it is hoped that the negative behaviour of the young offenders is altered and the positive self-concept is well maintained in order to become a law-abiding citizen in the future.

\section{Acknowledgments}

The authors would like to acknowledge the Malaysia Department of Social Welfare for allowing the researchers to conduct this study (JKMM 100/12/2/2:2016/013). Appreciation is also extended to the Universiti Malaysia Sarawak for funding the publication of this research.

\section{Conflict of Interest}

There is no conflict of interest regarding the publication and authorship of this article. 


\section{References}

Abele, A. E., \& Hauke, N. (2020). Two faces of the self: actor-self perspective and observer-self perspective are differentially related to agency versus communion. Journal Self and Identity, 19(3): 346-368.

Augustyn, M. B., \& Jackson, D. B. (2017). An intersectional look at the "rush to adulthood": considering the role of gender, race and SES in the link between precocious transitions and adult antisocial behavior. Youth \& Society, 1-24.

Belhekar, V. M. (2016). Statistics for psychology using $R\left(1^{\text {st }}\right.$ Ed.) SAGE Publication Inc.

Burris, C., \& Edwards, S. (2017). “Does facial width-to-height ratio predict male offender aggression?" Journal of Criminal Psychology, 7(4): 280-286.

Child act 2001. (2001). Laws of Malaysia. Retrieved from; http://www.agc.gov.my/agcportal/uploads/files/Publications/LOM/EN/Act\%20611.pdf

Chu, Y. W. (2017). The relationship between domain-specific self-concept and global self-esteem among adolescent in Taiwan. Educational Psychology, 33(2): 103-124.

Cohen, L., Manion, L., \& Marrison, K. (2001). Research methods in education (5 ${ }^{\text {th }}$ Ed.). London: Routledge Falmer.

Community Service Order Report. (2018). Department of social welfare. Retrieved from; http://www.jkm.gov.my/jkm/index.php?r=portal/full\&id=em9FSUd5UFBrYldlYXZHc3hKMCtkd z09

Debono, A., Corley, N., \& Muraven, M. (2020). Why am I left out? Interpretation of exclusion affect antisocial and prosocial behaviors. The American Journal of Psychology, 133(1): 63-79.

Edwardes, M. P. J. (2019). What is a self? There and back again. An Anthropological Perspective, 163189.

Fleming, J. S., \& Courtney, B. E. (1984). Multidimensional self-concept scale. Journal of Social Psychology, 14: 9-12.

Human Rights in the administration of justice. (2019). Retrieved from; https://www.ohchr.org/Documents/Publications/training9chapter9en.pdf.

Koiv, K. (2016). Perceived multiple emotional self-concept in groups of juvenile delinquent and nondelinquents. Procedia, Social and Behavioural Sciences, 217: 49-56.

Laceulle, H. (2018). Aging and self-realization. Trabscriot Verlag, 93-126.

Mohammadi, E., Ghasemi, M. A., Jafari, M. R., \& Rad, M. R. (2014). Evaluation the Relation between Self-Esteem and Social Adjustment Dimensions in High school Female Students of Iran (Case Study: Isfahan, 2013-14 Academic Years). International Journal of Academic Research in Psychology, 1(2), 43-49.

Mata, R., Frey, R., Richter, D., Schupp, J., \& Hertwig, R. (2018). Risk preference: a view from psychology. The Journal of Economic Perspectives, 32(2): 155-172.

Meldrum, R. C., Connolly, G. M., Flexon, J., \& Guerette, R. T. (2016). Parental low self-control, family environment, and juvenile delinquency. International Journal of Offender Therapy and Comparative Criminology, 60(4): 1-22.

Minor offences act 1955 (Act 336). (1995). Laws of Malaysia. Retrieved from; http://www.agc.gov.my/agcportal/uploads/files/Publications/LOM/EN/Act\%20336.pdf. 
Oluwasanmi, L. A., \& Babatola, M. A. (2018). A comparative study of the self-concept of inmates and the normal (non-inmates) in Nigeria. IOSR Journal of Humanities and Social Sciences, 23(5): 6568.

Paterline, B. A., \& Orr, D. (2016). Adaptation to prison and inmate self-concept. Journal of Psychology and Behavioural Science, 4(2): 70-79.

Phelps, M. S. (2018). Ending mass probation: sentencing, supervision, and revocation. Justice System Inequality, 28(1): 125-146.

Rosenberg, M. (1979). Social psychology: Sociological perspectives. New York: Basic.

Schildberg-Horisch, H. (2018). Are risk preferences stable? Journal of Economic Perspectives, 32(2): 135-154.

Skardhamar, T., Savolainen, J., Aase, K. N., \& Lyngstad, T.H. (2015). Does marriage reduce crime? The University of Chicago Press, 385-446.

Veiga, F., \& Leite, A. (2016). Adolescents' self-concept short scale: a version of PHCSCS. Procedia, Social and Behavioural Sciences, 217: 631-637.

Vignoles, V. L., Owe, E., Becker, M., Smith, P. B., Easterbrook, M. J., Brown, R., \& Bond, M. H. (2016). Beyond the east-west dichotomy: global variation in cultural models of selfhood. Journal of Experimental Psychology: General, 145(8): 966-1000. 